\title{
Glucuronidation Pathway
}

National Cancer Institute

\section{Source}

National Cancer Institute. Glucuronidation Pathway. NCI Thesaurus. Code C63811.

An inactivating and detoxification pathway for a variety of exogenous and endogenous molecules, including drugs, pollutants, bilirubin, androgens, estrogens, mineralocorticoids, glucocorticoids, fatty acid derivatives, retinoids and bile acids. Glucuronic acid is highly soluble in water and is often linked to poisonous substances to allow for subsequent elimination and to hormones to allow for easier transport. Also, drugs are commonly conjug ated to glucuronic acid to allow for easier delivery. Excretion occurs via urine or bile. 